\title{
Distinctive phonological features differ in relevance for both spoken and written word recognition
}

\author{
Mirjam Ernestus* and Willem Marinus Mak \\ Max Planck Institute for Psycholinguistics, Nijmegen University, P.O. Box 310, AH Nijmegen 6500, The Netherlands
}

Accepted 3 December 2003

Available online 18 February 2004

\begin{abstract}
This paper discusses four experiments on Dutch which show that distinctive phonological features differ in their relevance for word recognition. The relevance of a feature for word recognition depends on its phonological stability, that is, the extent to which that feature is generally realized in accordance with its lexical specification in the relevant word position. If one feature value is uninformative, all values of that feature are less relevant for word recognition, with the least informative feature being the least relevant. Features differ in their relevance both in spoken and written word recognition, though the differences are more pronounced in auditory lexical decision than in self-paced reading.
\end{abstract}

(C) 2003 Elsevier Inc. All rights reserved.

Keywords: Spoken and visual word recognition; Phonological distinctive features; Phonological stability; Dutch

\section{Introduction}

Under natural conditions, words are regularly presented in non-prototypical shapes, as the result of assimilations, neutralizations, mispronunciations, typos, or illegible handwritings. Previous research suggests that the number of mismatching distinctive phonological features affects the ease of both spoken (e.g., Connine, Blasko, \& Titone, 1993; Milberg, Blumstein, \& Dworetzky, 1988) and written (Lukatela, Eaton, Lee, \& Turvey, 2001) word recognition. If the number of mismatching features is larger, it is more difficult to recognize a word. It is more difficult to recognize sook than pook as book, because sook differs in two features from book, and pook in only one.

In this paper, we discuss whether phonological distinctive features are equally relevant for word recognition. More specifically, we address the question whether the relevance of a feature depends on its phonological stability, which we define as the extent to which the feature is generally realized in accordance with its specification in the mental lexicon. A feature's phono-

\footnotetext{
${ }^{*}$ Corresponding author. Fax: +31-2435-21-213.

E-mail address: mirjam.ernestus@mpi.nl (M. Ernestus).
}

logical stability is lower when it is less often realized in accordance with its lexical specification. Thus, in English, place of articulation has a lower phonological stability than [voice], since place is prone to assimilation, whereas voice is not (e.g., Jensen, 1993). We may expect that listeners and readers rely more upon features that are more stable, as these features provide the most valid cues. Moreover, if the lexical values of one and the same feature (the values that the feature may have in the lexical representations of words) differ in phonological stability, for instance, because only one value is involved in assimilation processes, we may also expect that speakers and listeners rely especially on the stable surface value, which is informative about the lexical value of the feature. Some support for the effect of phonological stability comes from Miller and Nicely (1955). They found that in English, where voice is more stable than place, the classification of voice is little affected by low-pass and noisy systems, whereas the classification of place of articulation is severely affected.

We report one auditory lexical decision experiment and three self-paced reading experiments, investigating the relevance of the distinctive phonological features voice, manner of articulation, and place of articulation 
in word recognition in Dutch. We concentrate on both fricatives and plosives in word-initial position.

For word-initial fricatives, voice is less stable than manner and place of articulation in Dutch. Dutch has no phonological processes affecting the manner or place of articulation of consonants, whereas some phonological processes affect the voice specifications of wordinitial fricatives. As a result of these processes, lexically voiced fricatives are regularly realized as unvoiced in word-initial position. After obstruents, they are obligatorily realized as unvoiced (e.g., Booij, 1995, p. 58), and in utterance-initial position they also tend to be unvoiced. Thus, een zwaard 'a sword' is realized with [z], but het zwaard ('the sword') is invariably realized with [s], and zwaard in isolation also tends to be realized with [s]. In addition, speakers of some varieties of Dutch realize all /z/'s and /v/'s as unvoiced (Collins \& Mees, 1981; Gussenhoven \& Bremmer, 1983).

In contrast to lexically voiced fricatives, lexically unvoiced fricatives are generally realized in accordance with their lexical representations. This means that only an unvoiced realization of a word-initial fricative is uninformative. A voiced realization is informative, as it implies a lexically voiced representation. In the auditory lexical decision experiment, we compared lexically voiced and unvoiced fricatives in order to ascertain if the phonological stability of one value affects the relevance of the other value of the same feature.

In contrast to fricatives, plosives are generally realized in accordance with their lexical representations in word-initial positions. They are always realized as plosives with the lexically specified voice and place of articulation in these positions. In word final positions, however, voice is not stable for plosives, as final plosives, independently of their lexical representations, are realized as voiced before voiced plosives, and as unvoiced in all other contexts. If the phonological stability that determines a feature's relevance is the phonological stability in the relevant position in the word, the three features voice, manner, and place would be equally relevant for plosives in word-initial position. If, in contrast, the stability that determines a feature's rele- vance is its general stability in all positions, voice may be less relevant than manner and place for plosives, also in word-initial positions. We compared voice with manner and with place for word-initial plosives in order to ascertain whether a feature's general or specific phonological stability affects its relevance for word recognition.

In addition to comparing voice with both manner and place of articulation, we also compared manner and place of articulation with each other. These features do not differ in their phonological stability, but they may nevertheless differ in their relevance for word recognition, because of some other property.

\section{Experiment 1}

In Experiment 1 we investigated the relevance of voice, manner, and place of articulation in auditory lexical decision. We split up the discussion of this experiment in three parts. We compare voice with manner in Experiment 1a, voice with place in Experiment 1b, and manner with place of articulation in Experiment $1 \mathrm{c}$ (see Table 1).

\subsection{Method}

\subsubsection{Materials}

For each subexperiment, we selected 32 monomorphemic words with the initial obstruents /z/, /s/, /v/, /f/, $/ \mathrm{b} /, / \mathrm{p} /, / \mathrm{d} /$, or $/ \mathrm{t} /$, each initial segment being represented by four words (see Appendix A). A male speaker recorded the words on a DAT (BASF master 94) in a soundproof room by means of a portable DAT-recorder Aiwa HD S100 and a Sony microphone ECM MS957. The recordings were stored as .wav files (sample rate: $48 \mathrm{kHz}$ ) on a computer by means of the speech analysis package Praat (Boersma, 1996).

Our speaker recorded four versions of each word (see Table 1 and the Appendix A). In the first version, the realization of the initial segment corresponded with its lexical representation. In the second version, the initial

Table 1

Outline of experiments with examples

\begin{tabular}{llll}
\hline Experiment & Incorrect Realization 1 & Incorrect Realization 2 & Incorrect Realization 3 \\
\hline $\begin{array}{l}\text { 1a, } 2 \\
\text { fricative }\end{array}$ & incorrect voice & incorrect manner & incorrect voice and manner \\
plosive & voto & poto & boto \\
dulp & sulp & foto ('photo') \\
$1 \mathrm{~b}, 3$ & incorrect voice & incorrect place & incorrect voice and place \\
fricative & zalto & falto & valto \\
plosive & torp & borp & porp \\
$\begin{array}{l}\text { lc, } 4 \\
\text { fricative }\end{array}$ & incorrect manner & incorrect place & incorrect manner and place \\
plosive & barken & zarken & darken \\
\hline
\end{tabular}


segment was realized with the opposite voice specification for Experiments $1 \mathrm{a}$ and $1 \mathrm{~b}$, or an initial fricative was realized as a plosive, or vice versa, for Experiment 1c (incorrect manner). In the third version, the initial consonant was realized with the incorrect manner for Experiment 1a, or a labial obstruent was realized as an alveolar obstruent, or vice versa, for Experiments $1 \mathrm{~b}$ and 1c (incorrect place). Finally, in the fourth version, the initial obstruent was realized with incorrect voice and manner for Experiment 1a, with incorrect voice and place for Experiment 1b, and with incorrect manner and place for Experiment 1c. For instance, our speaker recorded foto 'picture' (lexical), voto (incorrect voice), poto (incorrect manner), and boto (incorrect voice and manner) for Experiment 1a, dorp 'village' (lexical), torp (incorrect voice), borp (incorrect place), and porp (incorrect voice and place) for Experiment 1b, and varken 'pig' (lexical), barken (incorrect manner), zarken (incorrect place), and darken (incorrect manner and place) for Experiment 1c. None of the non-lexical realizations represent existing words in Dutch. The realizations were checked by two trained phoneticians.

We created four lists of words. Each list contained only one version of each word, and, for every subexperiment, one version type for each initial obstruent. The different versions of a word occupied the same positions in the different lists. Each list contained 155 fillers-101 existing words and 54 pseudowords - and was preceded by 10 practice items.

\subsubsection{Procedure}

Participants listened to the stimuli over headphones (Sennheiser HD 210), and decided as fast as possible whether a stimulus was an existing Dutch word (auditory lexical decision). They made their decision known by pressing a "yes" or "no" button. Each item was preceded by a beep of $400 \mathrm{~Hz}$ for $500 \mathrm{~ms}$. The item followed $200 \mathrm{~ms}$ after this beep. The reaction times were measured from word offset, and time out was set to $2500 \mathrm{~ms}$.

The practice items were followed by a break, and so were each 62 items in the actual experimental lists, such that there were three breaks in each session in total. Every break lasted as long as the participant wished, with a minimum of 3 min.

\subsubsection{Participants}

Forty participants were paid to participate in the experiment. All participants were native speakers of Dutch, and grew up in areas where voiced fricatives are distinguished from their unvoiced counterparts. Most participants were undergraduates at the Nijmegen University. Each list was presented to 10 participants.

\subsection{Results and discussion}

We considered as correct the word responses to the lexical realizations of the words, and the non-word responses to the non-lexical realizations. We concentrated on the responses to the non-lexical realizations, as these realizations are especially relevant for our research question. Given the phonological stability of the features, we predicted that voice is less relevant for word recognition than manner and place, and consequently that realizations with incorrect voice are more word-like than realizations with incorrect manner of place. Listeners therefore may have more problems classifying realizations with incorrect voice as non-words than realizations with incorrect manner or place. As a consequence, realizations with incorrect voice will more often be incorrectly classified as existing words. In addition, we may expect that listeners have more problems classifying realizations as non-words when the initial consonant has only an incorrect voice than when it also has an incorrect manner or place of articulation. We tested the two hypotheses with one-tailed t-tests, if general analyses of variances taking all version types into account gave us reasons to do so. Bonferroni adjustment was applied to the resulting $p$ values.

Previous literature (Connine et al., 1993; Milberg et al., 1988) suggests that a higher number of mismatching features makes word identification more difficult. If this hypothesis is correct, realizations with only an incorrect manner or place specification should be more word-like, and therefore harder to classify, than realizations that also have an incorrect voice. However, given our hypothesis that phonological stability is the determining factor in sublexical processing, we expect no difference between these realizations, because both involve one incorrect stable feature. We compared these version types also with one-tailed $t$ tests.

Table 2

Mean percentages of correct responses and mean response latencies (in ms) of the correct responses for the four realization variants of the fricativeand plosive-initial words in Experiment 1a

\begin{tabular}{|c|c|c|c|c|}
\hline & \multicolumn{2}{|c|}{ Percentages correct responses } & \multicolumn{2}{|c|}{ Mean RTs (ms) for correct responses } \\
\hline & Fricatives & Plosives & Fricatives & Plosives \\
\hline Lexical & 96.9 & 100 & 375 & 384 \\
\hline Incorrect voice & 58.8 & 94.4 & 647 & 513 \\
\hline Incorrect manner & 97.5 & 98.8 & 476 & 509 \\
\hline Incorrect voice and manner & 91.3 & 96.9 & 491 & 450 \\
\hline
\end{tabular}




\subsubsection{Results and discussion Experiment 1a}

Percentages of correct responses. Table 2 shows the percentages of correct responses and the mean reaction times of these correct responses for Experiment 1a, which compared voice with manner of articulation. We analyzed the numbers of correct and incorrect responses by means of two analyses of variance, one with participant means $\left(F_{1}\right)$ and one with item means $\left(F_{2}\right)$ as the random variable. We considered as independent variables Realization variant (lexical, incorrect voice, incorrect manner, incorrect voice and manner), and the lexical manner of articulation of the initial consonant (fricative, plosive). Both analyses showed a main effect of Realization variant $\left(F_{1}(3,37)=20.38, p<.001\right.$; $\left.F_{2}(3,28)=13.11, p<.001\right)$, and an interaction between Realization variant and the manner of the initial consonant $\left(F_{1}(3,37)=13.58, \quad p<.001 ; \quad F_{2}(3,28)=7.84\right.$, $p=.001)$. Realization variant was significant for fricatives $\left(F_{1}(3,37)=20.54, \quad p<.001 ; \quad F_{2}(3,13)=12.67\right.$, $p<.001)$, whereas it was significant for the plosives only in the participant analysis $\left(F_{1}(3,37)=5.134, p=.005\right.$; $\left.F_{2}(3,13)=2.32, p>.1\right)$.

For the fricative-initial words incorrect voice elicited more incorrect responses than incorrect manner $\left(t_{1}(39)=\right.$ $\left.-7.54, p<.001 ; t_{2}(15)=-6.34, p<.001\right)$. Hence, participants tended to pay little attention to incorrect voice, which suggests that voice is less relevant than manner for lexical fricatives in auditory word recognition.

We tested the relevance of the two different values of the feature voice (voiced and unvoiced), as only the unvoiced realizations are uninformative. Analyses of variance comparing only the responses to realizations with incorrect voice and those with incorrect manner for the fricative-initial words, including the lexical voice specification of the initial fricative as a factor, revealed a main effect of Realization variant $\left(F_{1}(1,19)=56.87, p<.001\right.$; $\left.F_{2}(1,14)=51.59, p<.001\right)$, and an interaction of Realization variant with lexical voice $\left(F_{1}(1,39)=16.25\right.$, $\left.p<.001 ; F_{2}(1,14)=5.41, p=.036\right)$. Participants incorrectly classified a word more often as an existing word, if it had an incorrect voice than if it had an incorrect manner, both for the words with lexically voiced fricatives $\left(t_{1}(39)=-8.45, p<.001 ; t_{2}(7)=-5.18, p<.001\right)$, and those with lexically unvoiced fricatives $\left(t_{1}(39)=-4.42\right.$, $\left.p<.001 ; t_{2}(7)=-6.25, p<.001\right)$. The interaction shows that this difference is larger for the lexically voiced than for the lexically unvoiced realizations (51\% vs. $26 \%$ ).

For the fricative-initial words, incorrect voice also elicited more incorrect responses than incorrect voice and manner $\quad\left(t_{1}(39)=-587, \quad p<.001 ; \quad t_{2}(15)=-3.74\right.$, $p=.002)$. In contrast, incorrect voice and manner differs from incorrect manner only in the participant analysis $\left(t_{1}(39)=2.91, p=.006 ; t_{2}(15)=1.14, p>.1\right)$, with incorrect manner eliciting more, instead of fewer, correct responses. This pattern of results is in line with our hypothesis.
For plosives, the difference between incorrect voice and incorrect manner was significant in the participant analysis only $\left(t_{1}(39)=-2.21, p=.034 ; t_{2}(15)=-1.24\right.$, $p>.1)$. The numbers of correct responses did not differ between incorrect voice and incorrect voice and manner ( $p>.29$, in both the participant and item analyses). Voice and manner do not differ in their relevance for word-initial plosives.

Reaction times. Analyses of the reaction times for the correct responses showed similar patterns. Both the participant and the item analysis showed a main effect of Realization variant $\quad\left(F_{1}(1,34)=8.99, \quad p=.005\right.$; $\left.F_{2}(3,27)=15.13, p<.001\right)$. The participant analysis also showed an interaction between Realization variant and the manner of the initial consonant (plosive or fricative: $\left.F_{1}(3,32)=5.408, p=.004\right)$, which was marginally supported by the item analysis $\left(F_{2}(3,27)=2.30\right.$, $p=.100)$. Realization variant affected the reaction times both for the fricative-initial words $\left(F_{1}(3,32)=22.31\right.$, $\left.p<.001 ; F_{2}(3,12)=8.75, p=.002\right)$, and the plosiveinitial words $\left(F_{1}(3,37)=12.88, p<.001 ; F_{2}(3,13)=\right.$ 9.03, $p=.002)$.

One-tailed $t$ tests on item and participant means showed that for the fricative-initial words incorrect voice elicited slower responses than incorrect manner $\left(t_{1}(34)=4.99, p<.001 ; t_{2}(14)=4.20, p<.001\right)$. Hence, the listeners delayed more in case of an incorrect voice, which suggests that they relied more upon manner. An analysis of variance comparing incorrect voice with incorrect manner for the fricative-initial words, including the factor lexical voice specification of the fricative, showed a main effect of Realization variant $\left(F_{1}(1,22)=\right.$ $\left.14.91, p=.001 ; F_{2}(1,13)=20.07, p=.001\right)$, and no interaction between Realization variant and the lexical voice specification of the fricative $\left(F_{1}(1,22)=3.04\right.$, $\left.p=.09 ; F_{2}(1,13)=2.29, p>.10\right)$. Voice is less relevant for lexically voiced and unvoiced fricatives, even though only unvoiced realizations are uninformative.

As predicted, also the difference between incorrect voice and incorrect manner and voice was statistically significant for the fricative-initial words $\left(t_{1}(34)=4.99\right.$, $\left.p<.001 ; t_{2}(14)=3.92, p=.001\right)$. In contrast, also as predicted, the difference between incorrect manner and incorrect voice and manner was not significant $(p>.76$ in the participant and item analyses). These results show that not the number of incorrect features but the phonological stability of the features is the determining factor in sublexical processing.

For the plosive-initial words, reaction times did not differ between incorrect voice and incorrect manner ( $p>.086$ in the participant and item analyses). The difference between incorrect manner and incorrect voice and manner was significant in the participant analysis only $\left(t_{1}(39)=2.49, p=.017 ; t_{2}(15)=1.38, p=.19\right)$. Voice and manner specifications appear not to differ in their relevance for plosives in word-initial position. 
We conclude that voice is a less relevant feature than manner of articulation for word-initial fricatives in Dutch spoken word recognition, whereas the two features hardly differ in their relevance for word-initial plosives. Recall that voice and manner differ in phonological stability for fricatives in word-initial position, the position under investigation in this experiment. For plosives, the two features differ in phonological stability only in word final position. Our results suggest therefore that the relevance of a feature in auditory word recognition depends especially on its phonological stability in the relevant prosodic position.

Although primarily lexically voiced fricatives are phonologically unstable, the voice specification of both voiced and unvoiced realizations of initial fricatives is a less relevant cue for lexical identification than manner. This suggests that if one value of a feature is uninformative, all values of that feature are less relevant for auditory word recognition. In addition, listeners rely even less on the least informative value of that feature.

\subsubsection{Results and discussion Experiment $1 b$}

Percentages of correct responses. Table 3 shows the percentages of correct responses for Experiment $1 \mathrm{~b}$, which compared voice with place of articulation. Analyses of variance showed a main effect of Realization variant (lexical, incorrect voice, incorrect place, incorrect voice and place: $F_{1}(1,37)=17.44, p<.001 ; F_{2}(3,28)=$ $16.71, p<.001)$, and an interaction between Realization variant and the manner of articulation of the initial consonant (fricative, plosive: $F_{1}(1,37)=10.28, p<.001$; $\left.F_{2}(3,28)=13.85, p<.001\right)$. Realization variant only affected the responses to the fricative-initial words $\left(F_{1}(3,37)=15.47, p<.001 ; F_{2}(3,13)=23.52, p<.001\right)$. The responses to the plosive-initial words were not affected by Realization variant (both $F \mathrm{~s}<1$ ).

For the fricative-initial words, $t$ tests showed that incorrect voice elicited significantly more incorrect responses than incorrect place $\left(t_{1}(39)=-6.65, p<.001\right.$; $\left.t_{2}(15)=-7.38, p<.001\right)$. The listeners relied less on the voice information than on the place information in the signal.

Analyses of variance for the fricative-initial words only comparing the responses to realizations with incorrect voice and those with incorrect place, and including the lexical voice specification of the initial fricative, revealed a main effect of Realization variant $\left(F_{1}(1,39)=44.26, p<.001 ; F_{2}(1,14)=66.48, p=.056\right)$, and an interaction between Realization variant and lexical voice $\left(F_{1}(1,39)=12.63, p<.001 ; F_{2}(1,14)=4.34\right.$, $p=.056)$. Realization variant affected the responses to the lexically voiced (incorrect voice vs. incorrect manner: $\left.t_{1}(39)=-7.37, p<.001 ; t_{2}(7)=-5.94, p=.001\right)$ and unvoiced fricatives $\left(t_{1}(39)=-4.66, p<.001 ; t_{2}(7)=\right.$ $6.00, p=.001)$, but the lexically voiced fricatives were affected to a greater extent (52\% vs. $29 \%)$. Listeners relied less upon unvoiced realizations, which are less informative.

Reaction times. Table 3 also shows the mean reaction times of the correct responses for the four realization variants. Analyses of variance showed an effect of Realization variant $\left(F_{1}(3,29)=16.55, \quad p<.001\right.$; $\left.F_{2}(3,28)=22.82, p<.001\right)$, and no interaction between Realization variant and the manner of articulation of the initial consonant (fricative, plosive: both $F_{\mathrm{S}}<1$ ).

Reaction times were longer for incorrect voice than for incorrect place $\left(t_{1}(39)=3.02, \quad p=.004\right.$; $\left.t_{2}(31)=2.49, p=.018\right)$, which suggests that the listeners based their decision more on the place than on the voice information in the signal. The reaction times were also significantly longer for incorrect voice than for incorrect voice and place $\left(t_{1}(39)=3.33, p=.002 ; t_{2}(31)=2.82\right.$, $p=.004)$. They did not differ between incorrect place and incorrect voice and place $\left(t_{1}(39)=-1.65, p=.053\right.$; $\left.t_{2}(31)=-1.39, p=.088\right)$. These results show that voice is less relevant than place for auditory word recognition.

Although the interaction between Realization variant and the manner of articulation of the initial consonant was not significant in the analyses of variance, we carried out separate $t$ tests for the fricative and the plosiveinitial words, as we had attested an interaction in the percentages of correct responses. For the fricatives, the reaction times were longer for incorrect voice than for incorrect place $\left(t_{1}(31)=2.60, p=.014 ; t_{2}(15)=2.19\right.$, $p=.044)$. There was no such difference for the plosiveinitial words $\left(t_{1}(39)=1.08, \quad p>.1 ; \quad t_{2}(15)=1.31\right.$, $p>.1)$. The difference between incorrect voice and incorrect place is mainly evidenced by the fricatives.

Finally, we carried out analyses of variance comparing the incorrect voice realizations with the incorrect place realizations for the fricative-initial words, distinguishing between lexically voiced and unvoiced

Table 3

Mean percentages of correct responses and mean response latencies (in $\mathrm{ms}$ ) of the correct responses for the four realization variants of the fricativeand plosive-initial words in Experiment $1 \mathrm{~b}$

\begin{tabular}{lcclcc}
\hline & \multicolumn{2}{l}{ Percentages correct responses } & & \multicolumn{2}{c}{ Mean RTs (ms) for correct responses } \\
\cline { 2 - 3 } \cline { 5 - 6 } & Fricatives & Plosives & & Fricatives & Plosives \\
\hline Lexical & 98.8 & 95.0 & 356 & 360 \\
Incorrect voice & 58.8 & 93.8 & 614 & 533 \\
Incorrect place & 96.9 & 93.8 & 492 & 493 \\
Incorrect voice and place & 100 & 95.6 & 467 & 501 \\
\hline
\end{tabular}


fricatives. We found main effects for Realization variant $\left(F_{1}(1,23)=44.26, p<.001 ; F_{2}(1,14)=5.65, p=.032\right)$, and an interaction between Realization variant and the lexical voice specification of the fricative $\left(F_{1}(1,23)=\right.$ $\left.12.63, p=.001 ; F_{2}(1,14)=3.60, p=.079\right)$. Incorrect voice and incorrect place differed for the lexically voiced fricatives $\left(t_{1}(23)=3.07, p=.005 ; t_{2}(7)=3.15, p=.016\right)$, whereas they did not differ for the unvoiced fricatives ( $p>.29$ in the participant and item analyses). The listeners did not heavily rely on the uninformative, unvoiced realizations of the lexically voiced fricatives.

In conclusion, listeners classify fricative-initial words more often as existing words, if the fricative has been realized with incorrect voice than if it has been realized with incorrect place of articulation. No such difference in percentages of correct responses was found for the plosive-initial words. In addition, we found that listeners hesitated less when there is a mismatch in place than in voice, and also this difference seems to be greater for the fricatives. The differences between fricatives and plosives support our conclusion from Experiment 1a that the relevance of a feature for auditory word recognition is especially affected by its phonological stability in the relevant word position. Finally, as in Experiment 1a, the percentages of correct responses show that voice is less relevant both for the lexically voiced and unvoiced fricatives, which supports the hypothesis that if one feature value is uninformative, both values of the feature are less relevant. In addition, listeners rely the least on the least informative value of the feature.

\subsubsection{Results and discussion Experiment $1 c$}

Percentages of correct responses. The percentages correct responses to the stimuli in subexperiment $1 \mathrm{c}$ are listed in Table 4. This subexperiment compared manner and place. Analyses of variance showed no main effect of Realization variant (lexical, incorrect manner, incorrect place, incorrect manner and place: $F_{1}(3,37)=$ $\left.1.20, p>.1 ; F_{2}(3,28)=1.17, p>.1\right)$, and no interaction between Realization variant and the manner of the word-initial consonant $\left(F_{1}(3,37)=2.49, \quad p=.075\right.$; $\left.F_{2}(3,28)=1.31, p>.1\right)$.

Reaction times. The reaction times (see Table 4 for the means) revealed a main effect of Realization variant $\left(F_{1}(3,37)=24.90, p<.001 ; F_{2}(3,28)=21.90, p<.001\right)$, and no interaction between Realization variant and the lexical manner of articulation of the initial consonant $\left(F_{1}(3,37)=1.78, p>.1 ; F_{2}(3,28)=.97, p>.1\right) . T$ tests showed that the incorrect realizations of the words did not differ from each other. The main effect of Realization variant resulted from the differences between the lexical realizations and the non-lexical representations. We conclude that Experiment 1c provided no evidence for a difference between manner and place of articulation in their relevance for auditory word recognition. This finding corresponds with the fact that these features also do not differ in their phonological stability.

\subsubsection{General conclusions and discussion}

In summary, Experiment 1 has shown that distinctive features may differ in their relevance for auditory word recognition. In Dutch, voice is less relevant for fricatives in word-initial position than manner and place of articulation, which corresponds with the weak phonological stability of voice and the strong phonological stability of manner and place for fricatives. Listeners attach an even smaller value to voice in uninformative, unvoiced realizations of fricatives than in informative, voiced realizations, which means that they rely the least upon the least informative value of a feature. Both values are affected, however, by the uninformativeness of unvoiced realizations.

For plosives, voice seems to be approximately as relevant for the recognition of a word as manner and place. Since voice is phonologically as stable as manner and place of articulation for plosives in word-initial position, which is the position tested in this experiment, these results suggest that the phonological stability which determines the relevance of a feature is especially the phonological stability in the relevant word position.

In Experiments 2-4, we investigated the relevance of voice, manner, and place of articulation in written word recognition, as previous research has suggested that phonological distinctive features also play a role in reading (Lukatela et al., 2001). We chose the self-paced reading paradigm, since this paradigm allows for preceding context to facilitate the processing of an incorrect grapheme, and it therefore approaches natural written word recognition better than lexical decision. Experiments 2-4 compare the same distinctive phonological features as Experiments 1a-1c, respectively.

Table 4

Mean percentages of correct responses and mean response latencies (in ms) of the correct responses for the four realization variants of the fricativeand plosive-initial words in Experiment 1c

\begin{tabular}{llllll}
\hline & \multicolumn{2}{l}{ Percentages correct responses } & & \multicolumn{2}{l}{ Mean RTs (ms) for correct responses } \\
\cline { 2 - 3 } & Fricatives & Plosives & & Fricatives & Plosives \\
\hline Lexical & 94.4 & 99.4 & 350 & 320 \\
Incorrect manner & 97.5 & 95.6 & 481 & 516 \\
Incorrect place & 94.4 & 95.6 & 504 & 504 \\
Incorrect manner and place & 98.1 & 97.5 & 501 & 480 \\
\hline
\end{tabular}


Given the weak phonological stability of voice, we predicted that readers have less difficulty recognizing the intended word when the spelling reflects for the initial consonant an incorrect voice feature than when the spelling reflects an incorrect manner specification, or an incorrect place specification, independently of whether this incorrect manner or place specification is accompanied by an incorrect voice specification. We compared the reading times for these spellings by means of onetailed $t$ tests with Bonferroni adjustment, if the analyses of variance showed that the spelling of a word affected the reading times. We did not expect a difference between words spelled with only incorrect manner or place and words which were also spelled incorrectly with respect to voice. We compared these spellings also with one-tailed $t$ tests.

\section{Experiment 2}

In Experiment 2 we compared the relevance of voice with the relevance of manner of articulation both for fricatives and plosives in word-initial position (see Table 1).

\subsection{Method}

\subsubsection{Materials}

We selected 32 monomorphemic words starting with $/ \mathrm{b} /, / \mathrm{p} /, / \mathrm{d} /, / \mathrm{t} /, / \mathrm{z} /, / \mathrm{s} /, / \mathrm{v} /$, and $/ \mathrm{f} /$, each initial segment being represented by four words. The words were embedded in sentences. Each sentence consisted of a subject noun phrase, a verb form, a determiner, the target word, and a prepositional phrase. For instance, the word saus was embedded in De kok goot de saus over de aardappels "The cook poured the sauce over the potatoes." Each target word was spelled correctly in one version of the sentence (lexical), and misspelled in three other versions (see Appendix A). In these non-lexical versions, the initial consonant of the target word was spelled as having the incorrect voice specification (e.g., zaus instead of saus), the incorrect manner specification (e.g., taus instead of saus), or both the incorrect voice and manner specification (e.g., daus instead of saus). These incorrect spellings did not represent existing words of Dutch. The target word could be easily identified given the preceding context, also when it was misspelled. Apart from the initial grapheme of the target word, the four versions of a sentence were identical.

The four versions of the sentences gave a total of 128 experimental sentences. We divided them over four experimental lists, such that each list contained one version of every sentence, and one sentence for each version type for every initial segment. The 32 experimental sentences in each list were pseudorandomly mixed with 144 filler sentences, which were all spelled correctly. The versions of a sentence occupied the same position in each list. Every list was preceded by a block of 14 practice sentences.

Each sentence in the experiment was followed by a question about that sentence. The questions stimulated the participants to read the sentences carefully, and to focus on content instead of form.

\subsubsection{Procedure}

The participants performed a self-paced reading task. They were tested individually, sitting in a dimly lit room in front of a PC monitor, and a panel with three buttons. The course of a trial was as follows. The participant saw a fixation point, indicating the starting position of all sentences. The participant pressed the middle button, and a complete sentence was presented on the screen. The letters, however, had been replaced by dashes. Only the full stop at the end of the sentence was visible. The participant pressed the middle button, and the dashes of the first word were converted into letters. The participant read this word, and pressed the middle button again, which reconverted the letters of the first word into dashes, and made the second word legible. The participant read this word, pressed the button, and read the following word. This was repeated until the participant had read all words of the sentence. The participant then saw the word vraag "question" for $1.0 \mathrm{~s}$ on the screen, followed by the question about the sentence. If the answer to the question was 'yes,' the participant pressed the "yes" button. If the answer was 'no,' the participant pressed the "no" button. We measured the time span between the successive button presses, that is, the time a participant needed to read each word in the sentence. The participants were told that some sentences contained misspellings, that they should ignore those, and that it would be clear from the context which word was intended.

\subsubsection{Participants}

Forty undergraduates from the Nijmegen University participated in the experiment. All were native speakers of Dutch, and none had participated in Experiment 1 .

\subsection{Results and discussion}

We discarded the extremely long (longer than $4000 \mathrm{~ms}$ ) and extremely short (shorter than $50 \mathrm{~ms}$ ) reading times. From the remaining reading times, we excluded those that were more than two standard deviations away from both the participant and item means for a given word in the given spelling variant. In total we discarded $1.2 \%$ of reading times.

Table 5 shows the average resulting reading times for the target words and the directly following words for the four spelling variants, distinguishing between fricative and plosive-initial words. We took the words directly 
Table 5

The average reading times (in $\mathrm{ms}$ ) for the target word and the following word for the four spellings of the target word, separately for fricative- and plosive-initial target words, in Experiment 2

\begin{tabular}{llll}
\hline & Fricative & Plosive \\
\hline Target word & Lexical & 345 & 347 \\
& Incorrect voice & 385 & 387 \\
& Incorrect manner & 388 & 406 \\
& Incorrect voice & 391 & 379 \\
& and manner & & \\
Following & Lexical & 328 & 328 \\
word & Incorrect voice & 410 & 398 \\
& Incorrect manner & 429 & 433 \\
& Incorrect voice & 431 & 476 \\
& and manner & & \\
\hline
\end{tabular}

following the target words into account, since there are often spill-over effects to the following words in selfpaced reading tasks (Just, Carpenter, \& Woolley, 1982).

We carried out analyses of variance on the participant and item means with Position (target word, the following word), Spelling variant (lexical, incorrect voice, incorrect manner, incorrect voice and manner), and the manner of articulation of the initial consonant (fricative, plosive) as factors. The analyses showed main effects of Position $\left(F_{1}(1,39)=3.13, p<.085 ; F_{2}(1,30)=15.78, p<.001\right)$, and Spelling variant $\left(F_{1}(3,37)=22.24, \quad p<.001\right.$; $\left.F_{2}(3,28)=19.86, p<.001\right)$, and an interaction between Position and Spelling variant $\left(F_{1}(3,37)=6.10, p<.001\right.$; $\left.F_{2}(3,28)=9.26, p<.001\right)$. No interactions with the manner of articulation of the initial consonant were significant.

$T$ tests on the participant and item means showed no differences between the incorrect conditions at the target word. The word following the target word was read significantly faster for incorrect voice compared with incorrect manner $\left(t_{1}(39)=-2.55, \quad p=.016 ; \quad t_{2}(31)=\right.$ $-2.90, p=.008)$, and also compared with incorrect voice and manner $\left(t_{1}(39)=-3.87, p<.001 ; t_{2}(31)=-3.57\right.$, $p=.002)$. We attested no significant differences between incorrect manner and incorrect voice and manner.

We conclude that voice is less relevant than manner of articulation, also in written word recognition. In contrast to auditory lexical decision (see Experiment 1a), voice seems to be less relevant than manner both for the fricatives and the plosives in self-paced reading. One possible explanation for this difference may be that in written word recognition a feature's relevance is affected by its general phonological stability.

\section{Experiment 3}

In Experiment 3, we compared the relevance of voice with the relevance of place of articulation, both for word-initial fricatives and plosives (see Table 1).

\subsection{Method}

\subsubsection{Materials}

We selected again 32 monomorphemic words starting with /b/, /p/, /d/, /t/, /z/, /s/, /v/, and /f/, each initial segment being represented by four words. We created four versions of each word: the word was spelled correctly, or its initial consonant was spelled as having the incorrect voice specification, an incorrect place of articulation (labial instead of alveolar, or vice versa), or both the incorrect voice and place (see Appendix A). The incorrect spellings did not represent existing words. The words were embedded in sentences with the same structure as in Experiment 2, and the sentences were distributed over four experimental lists, also as in Experiment 2. The experimental items in each list were pseudorandomly mixed with 64 filler sentences, 16 of which contained misspelled verb forms. Every list started with 14 practice sentences. All sentences were followed by questions.

\subsubsection{Procedure}

The procedure was the same as in Experiment 2.

\subsubsection{Participants}

Forty native speakers of Dutch were paid for their participation. Most of them were undergraduate students of the Nijmegen University. None of them had participated in Experiment 1 or 2.

\subsection{Results and discussion}

We cleared the data set as in Experiment 2, which resulted in the exclusion of $1.0 \%$ of data points. Table 6 shows the resulting average reading times for the fricative and plosive-initial target words and their directly following words, broken down for the four spelling variants. Analyses of variance with Position (target word, following word), Spelling variant (lexical, incorrect voice, incorrect place, incorrect voice and place), and the manner of articulation of the initial consonant

Table 6

The average reading times (in $\mathrm{ms}$ ) for the target word and the following word for the four spellings of the target word, separately for fricative- and plosive-initial target words, in Experiment 3

\begin{tabular}{clll}
\hline & & Fricative & Plosive \\
\hline Target & Lexical & 361 & 348 \\
word & Incorrect voice & 410 & 385 \\
& Incorrect place & 442 & 421 \\
& Incorrect voice & 438 & 450 \\
& and place & & \\
Following & Lexical & 351 & 335 \\
word & Incorrect voice & 410 & 470 \\
& Incorrect place & 520 & 444 \\
& Incorrect voice & 469 & 457 \\
& and place & & \\
\hline
\end{tabular}


(fricative, plosive) showed a main effect of Position $\left(F_{1}(1,39)=9.79, p=.003 ; F_{2}(1,29)=26.99, p<.001\right)$, Spelling variant $\left(F_{1}(3,37)=20.55, p<.001 ; F_{2}(3,27)=\right.$ $25.69, p<.001)$, and an interaction for Position and Spelling variant $\left(F_{1}(3,37)=6.70, p=.001 ; F_{2}(3,27)=\right.$ $12.67, p<.001)$. The interaction between Spelling variant and manner of articulation of the initial consonant was significant in the participant analysis $\left(F_{1}(3,37)=\right.$ $\left.3.70, p=.020 ; F_{2}<1\right)$. The interaction of Position, Spelling Variant, and manner of articulation was marginally significant in the participant analysis $\left(F_{1}(3,37)=\right.$ $\left.2.65, p=.063 ; F_{2}(3,27)=1.70, p>.1\right)$.

$T$ tests on the participant and item means showed no differences between the incorrect conditions at the target word. At the word following the target word, the differences between incorrect voice and incorrect place were not statistically significant when we tested the fricative and plosive-initial words together. We also tested the two word types separately, because of the statistically significant interaction in the participant analysis. For the fricatives, we found a difference between incorrect voice and incorrect place at the word following the target word $\left(t_{1}(39)=-3.35, p=.004 ; t_{2}(14)=-3.15, p=.014\right)$. Moreover, incorrect voice differed from incorrect voice and place at this position $\left(t_{1}(39)=-3.10, p=.008\right.$; $\left.t_{2}(15)=-2.41, p=.058\right)$. These results show that voice and place differ for the fricatives.

We found no differences for the initial plosives. Recall that we also had found no large differences between incorrect voice and incorrect place for the initial plosives in the corresponding auditory lexical decision experiment (Experiment 1b). On the basis of this difference between fricatives and plosives, we concluded that especially the specific phonological stability of a feature for the relevant word position affects its relevance for auditory word recognition. Experiments 2 and 3 do not provide convincing evidence that the same also holds for written word recognition. The results from Experiment 2 suggest that readers overcome incorrect voice more easily than incorrect manner, also for plosive-initial words.

\section{Experiment 4}

We compared the relevance of manner and place of articulation in Experiment 4 (see Table 1).

\subsection{Method}

\subsubsection{Materials}

We selected again 32 monomorphemic nouns starting with /b/, /p/, /d/, /t/, /z/, /s/, /v/, and /f/, each initial segment being represented by four words, and again we created four versions for each word: the word was spelled correctly, or its initial consonant was spelled as having the incorrect manner specification, the incorrect place specification, or both the incorrect manner and place specification (see Appendix A). The incorrect spellings did not represent existing nouns of Dutch. The words were embedded in sentences with the same structure as in Experiments 2 and 3, and we also constructed four experimental lists as in Experiments 2 and 3. The experimental items were mixed with 108 filler sentences, 30 of which contained misspelled verb forms. All lists were preceded by 14 practice sentences, and each sentence was followed by a question.

\subsubsection{Procedure}

The procedure was the same as in Experiments 2 and 3.

\subsubsection{Participants}

Sixty native speakers of Dutch were paid for their participation. Most of them were undergraduate students of the Nijmegen University. None of them had participated in Experiment 1, 2, or 3.

\subsection{Results and discussion}

The data set was cleared as in Experiments 2 and 3. In total, we excluded $1.2 \%$ of reading times. Table 7 shows the resulting mean reading times for the target words and the directly following words, distinguishing between the different spelling variants. Analyses of variance with Position (target word, directly following word), Spelling variant (lexical, incorrect manner, incorrect place, incorrect manner and place), and the lexical manner of articulation of the word-initial consonant (fricative, plosive) as independent variables revealed a main effect for the Spelling variant $\left(F_{1}(3,57)=24.93, p<.001\right.$; $\left.F_{2}(3,28)=46.45, p<.001\right)$, and no interactions.

$T$ tests did not provide any evidence for a difference between incorrect manner and incorrect place $(p>.88$ in the participant and the item analyses). Hence, both the auditory lexical decision experiment and the self-paced reading experiment do not show any difference in relevance between manner and place of articulation in Dutch word recognition.

Table 7

The average reading times (in $\mathrm{ms}$ ) for the target word and the following word for the four spellings of the target word, separately for fricativeand plosive-initial target words, in Experiment 4

\begin{tabular}{clll}
\hline & & Fricative & Plosive \\
\hline Target & Lexical & 380 & 361 \\
word & Incorrect manner & 451 & 474 \\
& Incorrect place & 454 & 458 \\
& Incorrect manner & 471 & 449 \\
& and place & & \\
Following & Lexical & 341 & 324 \\
word & Incorrect manner & 461 & 420 \\
& Incorrect place & 468 & 409 \\
& Incorrect manner & 450 & 406 \\
& and place & & \\
\hline
\end{tabular}




\section{General discussion}

This study reports four experiments on Dutch testing the hypothesis that a feature's relevance is correlated with the extent to which that feature is phonologically stable, or informative, given the phonological and phonetic tendencies in the language. Experiment 1 showed that Dutch listeners rely less upon voice than upon manner and place of articulation for fricative-initial words. They tend to classify words realized with the non-lexical voice specification for the initial fricative as existing words, and, if they do classify them as nonwords, they need relatively much time. These results support the hypothesis that a feature's relevance is correlated with its phonological stability, as word-initial fricatives in Dutch are always realized in accordance with their lexical manner and place specifications, while lexically voiced fricatives are regularly realized as unvoiced. The listeners attached little value to voice in both the unvoiced and voiced realizations of fricatives, but nevertheless somewhat more in the voiced realizations. This shows that listeners rely little upon features of which at least one value is uninformative, and also that they rely the least on the least informative value.

We found no convincing evidence that Dutch listeners rely less on voice than on manner and place of articulation for word-initial plosives. Since voice is as stable as manner and place in word-initial position for plosives, and it is less stable only in word-final position, the relevance of a feature appears to be determined es- pecially by its phonological stability in the relevant prosodic position.

Experiments 2-4 showed that, especially for fricatives, voice is less relevant than manner and place of articulation also in written word recognition. Hence also in written word recognition, a feature's relevance correlates with its phonological stability. These results support earlier claims that visual word identification may involve a phonological (e.g., Coltheart, Curtis, Atkins, \& Haller, 1993), and even a subphonemic level (Lukatela et al., 2001). The relatively low relevance of voice, however, is somewhat less pronounced in the selfpaced reading experiments than in the auditory lexical decision experiment. This may be due to the presence of context in the reading experiment, which may help the language users overcome the feature mismatches. In addition, the less pronounced differences may be inherent to the reading task in which the orthographic form may provide direct lexical access (Coltheart et al., 1993).

In contrast to previous studies (Connine et al., 1993; Lukatela et al., 2001; Milberg et al., 1988), both our auditory lexical decision experiment and our self-paced reading experiments do not support the hypothesis that an increasing number of mismatching features increasingly hinders word identification. The relevance of the feature values is determinative, and the relevance of each feature value is affected by its phonological stability in the given prosodic position, and by the phonological stability of the other values of that same feature.

\section{Appendix A}

Items for Experiment 1a

\begin{tabular}{llll}
\hline Lexical & Incorrect voice & Incorrect manner & Incorrect voice \& manner \\
\hline fricatives & & & \\
salvo 'salvo' & zalvo & talvo & dalvo \\
saldo 'balance' & zaldo & taldo & daldo \\
saus 'sauce' & zaus & taus & daus \\
samba 'samba' & zamba & tamba & damba \\
zwaan 'swan' & swaan & dwaan & twaan \\
zorg 'care' & sorg & dorg & torg \\
zwaard 'sword' & swaard & dwaard & twaard \\
zieke 'sick' & sieke & dieke & tieke \\
fluitje 'flute' & vluitje & pluitje & bluitje \\
friet 'fries' & vriet & priet & briet \\
foto 'photo' & voto & poto & boto \\
fooi 'tip' & vooi & pooi & booi \\
venster 'window' & fenster & benster & penster \\
vloer 'floor' & floer & bloer & ploer \\
vlam 'flame' & flam & blam & plam \\
vlieg 'fly' & flieg & blieg & plieg \\
plosives & & & \\
toga 'toga' & doga & soga & zoga \\
tunnel 'tunnel' & dunnel & sunnel & zunnel
\end{tabular}


Appendix A (continued)

\begin{tabular}{llll}
\hline Lexical & Incorrect voice & Incorrect manner & Incorrect voice \& manner \\
\hline titel 'title' & ditel & sitel & zitel \\
tulp 'tulip' & dulp & sulp & zulp \\
dief 'thief' & tief & zief & sief \\
dood 'death' & tood & zood & sood \\
duif 'dove' & tuif & zuif & suif \\
duik 'dive' & tuik & zuik & suik \\
pater 'father' & bater & fater & vater \\
pekel 'brine' & bekel & fekel & vekel \\
prijs 'price' & brijs & frijs & vrijs \\
ploeg 'plough' & bloeg & floeg & vloeg \\
bank 'bank' & pank & vank & fank \\
beeld 'statue' & peeld & veeld & feeld \\
blaas 'bladder' & plaas & vlaas & flaas \\
boek 'book' & poek & voek & foek \\
\hline
\end{tabular}

Items for Experiment $1 \mathrm{~b}$

\begin{tabular}{|c|c|c|c|}
\hline Lexical & Incorrect voice & Incorrect place & Incorrect voice \& place \\
\hline \multicolumn{4}{|l|}{ fricatives } \\
\hline salto 'somersault' & zalto & falto & valto \\
\hline sekte 'sect' & zekte & fekte & vekte \\
\hline sieraad 'jewellery’ & zieraad & fieraad & vieraad \\
\hline soep 'soup' & zoep & foep & voep \\
\hline zadel 'saddle' & sadel & vadel & fadel \\
\hline zand 'sand' & sand & vand & fand \\
\hline zender 'sender' & sender & vender & fender \\
\hline zoen 'kiss' & soen & voen & foen \\
\hline feest 'party' & veest & seest & zeest \\
\hline firma 'firm' & virma & sirma & zirma \\
\hline filter 'filter' & vilter & silter & zilter \\
\hline folie 'foelie' & volie & solie & zolie \\
\hline vaart 'speed' & faart & zaart & saart \\
\hline vader 'father' & fader & zader & sader \\
\hline veld 'field' & feld & zeld & seld \\
\hline vorst 'frost' & forst & zorst & sorst \\
\hline \multicolumn{4}{|l|}{ plosives } \\
\hline takel 'tackle' & dakel & pakel & bakel \\
\hline tante 'aunt' & dante & pante & bante \\
\hline tekst 'text' & dekst & pekst & bekst \\
\hline toeter 'horn' & doeter & poeter & boeter \\
\hline diesel 'diesel' & tiesel & biesel & piesel \\
\hline darm 'bowel' & tarm & barm & parm \\
\hline deeg 'dough' & teeg & beeg & peeg \\
\hline dorp 'village' & torp & borp & porp \\
\hline page 'page' & bage & tage & dage \\
\hline pauze 'pause' & bauze & tauze & dauze \\
\hline peper 'pepper' & beper & teper & deper \\
\hline pauk 'kettledrum' & bauk & tauk & dauk \\
\hline bagger 'mud' & pagger & dagger & tagger \\
\hline basis 'basis' & pasis & dasis & tasis \\
\hline bende 'mess' & pende & dende & tende \\
\hline buidel 'pouch' & puidel & duidel & tuidel \\
\hline
\end{tabular}


Appendix A (continued)

Items for Experiment 1c

\begin{tabular}{|c|c|c|c|}
\hline Lexical & Incorrect manner & Incorrect place & Incorrect manner \& place \\
\hline $\begin{array}{l}\text { fricatives } \\
\text { sorbet 'sorbet' } \\
\text { servet 'napkin' } \\
\text { safari 'safari' } \\
\text { serie 'series' } \\
\text { zalf 'salf' } \\
\text { zegel 'seal' } \\
\text { zenuw 'nerve' } \\
\text { zetel 'seat' } \\
\text { feeks 'shrew' } \\
\text { fakkel 'torch' } \\
\text { fiets 'bicycle' } \\
\text { film 'film' } \\
\text { vaandel 'banner' } \\
\text { varken 'pig' } \\
\text { vogel 'bird' } \\
\text { vuist 'fist' }\end{array}$ & $\begin{array}{l}\text { torbet } \\
\text { tervet } \\
\text { tafari } \\
\text { terie } \\
\text { dalf } \\
\text { degel } \\
\text { denuw } \\
\text { detel } \\
\text { peeks } \\
\text { pakkel } \\
\text { piets } \\
\text { pilm } \\
\text { baandel } \\
\text { barken } \\
\text { bogel } \\
\text { buist }\end{array}$ & $\begin{array}{l}\text { forbet } \\
\text { fervet } \\
\text { fafari } \\
\text { ferie } \\
\text { valf } \\
\text { vegel } \\
\text { venuw } \\
\text { vetel } \\
\text { seeks } \\
\text { sakkel } \\
\text { siets } \\
\text { silm } \\
\text { zaandel } \\
\text { zarken } \\
\text { zogel } \\
\text { zuist }\end{array}$ & $\begin{array}{l}\text { porbet } \\
\text { pervet } \\
\text { pafari } \\
\text { perie } \\
\text { balf } \\
\text { begel } \\
\text { benuw } \\
\text { betel } \\
\text { teeks } \\
\text { takkel } \\
\text { tiets } \\
\text { tilm } \\
\text { daandel } \\
\text { darken } \\
\text { dogel } \\
\text { duist }\end{array}$ \\
\hline $\begin{array}{l}\text { plosives } \\
\text { tafel 'table' } \\
\text { tarwe 'wheat' } \\
\text { tempo 'speed' } \\
\text { tijger 'tiger' } \\
\text { delta 'delta' } \\
\text { danser 'dancer' } \\
\text { dieet 'diet' } \\
\text { dienst 'service' } \\
\text { post 'post' } \\
\text { park 'park' } \\
\text { parel 'pearl' } \\
\text { pels 'fur' } \\
\text { balie 'counter' } \\
\text { bami 'fried noodles' } \\
\text { bodem 'bottom' } \\
\text { boter 'butter' }\end{array}$ & $\begin{array}{l}\text { safel } \\
\text { sarwe } \\
\text { sempo } \\
\text { sijger } \\
\text { zelta } \\
\text { zanser } \\
\text { zieet } \\
\text { zienst } \\
\text { fost } \\
\text { fark } \\
\text { farel } \\
\text { fels } \\
\text { valie } \\
\text { vami } \\
\text { vodem } \\
\text { voter }\end{array}$ & $\begin{array}{l}\text { pafel } \\
\text { parwe } \\
\text { pempo } \\
\text { pijger } \\
\text { belta } \\
\text { banser } \\
\text { bieet } \\
\text { bienst } \\
\text { tost } \\
\text { tark } \\
\text { tarel } \\
\text { tels } \\
\text { dalie } \\
\text { dami } \\
\text { dodem } \\
\text { doter }\end{array}$ & $\begin{array}{l}\text { fafel } \\
\text { farwe } \\
\text { fempo } \\
\text { fijger } \\
\text { velta } \\
\text { vanser } \\
\text { vieet } \\
\text { vienst } \\
\text { sost } \\
\text { sark } \\
\text { sarel } \\
\text { sels } \\
\text { zalie } \\
\text { zami } \\
\text { zodem } \\
\text { zoter }\end{array}$ \\
\hline
\end{tabular}

Items for Experiment 2

\begin{tabular}{llll}
\hline Lexical & Incorrect voice & Incorrect manner & Incorrect voice \& manner \\
\hline fricatives & & & \\
saus 'sauce' & zaus & taus & daus \\
sage 'saga' & zage & tage & dage \\
servet 'napkin' & zervet & tervet & dervet \\
samba 'samba' & zamba & tamba & damba \\
zwaan 'swan' & swaan & dwaan & twaan \\
zorg 'care' & sorg & dorg & tetel \\
zetel 'seat' & setel & detel & twaard \\
zwaard 'sword' & swaard & dwaard & bluitje \\
fluitje 'whistle' & vluitje & pluitje & briet \\
friet 'fries' & vriet & priet & boto \\
foto 'photo' & voto & poto & booi \\
fooi 'tip' & vooi & pooi &
\end{tabular}


Appendix A (continued)

\begin{tabular}{llll}
\hline Lexical & Incorrect voice & Incorrect manner & Incorrect voice \& manner \\
\hline vloer 'floor' & floer & bloer & ploer \\
vlam 'flame' & flam & blam & plam \\
vlieg 'fly' & flieg & blieg & plieg \\
vlees 'meat' & flees & blees & plees \\
plosives & & & \\
taart 'cake' & daart & saart & zaart \\
tulp 'tulip' & dulp & sulp & zulp \\
titel 'title' & ditel & sitel & zitel \\
tafel 'table' & dafel & safel & zafel \\
dief 'thief' & tief & zief & sief \\
duif 'dove' & tuif & zuif & suif \\
duik 'dive' & tuik & zuik & suik \\
dood 'death' & tood & zood & sood \\
prijs 'price' & brijs & frijs & vrijs \\
post 'post' & bost & fost & vost \\
park 'park' & bark & fark & vark \\
ploeg 'plough' & bloeg & floeg & vloeg \\
bank 'bank' & pank & vank & fank \\
bami 'fried noodles' & pami & vami & fami \\
boek 'book' & poek & voek & foek \\
blaas 'bladder' & plaas & vlaas & flaas \\
\hline
\end{tabular}

Items for Experiment 3

\begin{tabular}{llll}
\hline Lexical & Incorrect voice & Incorrect place & Incorrect voice \& place \\
\hline fricatives & & & \\
salto 'somersault' & zalto & falto & valto \\
sekte 'sect' & zekte & fekte & vekte \\
sieraad 'jewellery' & zieraad & fieraad & vieraad \\
soep 'soup' & zoep & foep & voep \\
zadel 'saddle' & sadel & vadel & fadel \\
zand 'sand' & sand & vand & fand \\
zender 'sender' & sender & vender & fender \\
zoen 'kiss' & soen & voen & foen \\
feeks 'furie' & veeks & seeks & zeeks \\
file 'traffic jam' & vile & sile & zile \\
filter 'filter' & vilter & silter & zilter \\
folie 'foelie' & volie & solie & zolie \\
vaart 'speed' & faart & zaart & saart \\
vader 'father' & fader & zader & sader \\
veld 'field' & feld & zeld & seld \\
vorst 'frost' & forst & zorst & sorst \\
plosives & & & \\
takel 'tackle' & dakel & pakel & bakel \\
tante 'aunt' & dante & pante & bante \\
tekst 'text' & dekst & pekst & bekst \\
toeter 'horn' & doeter & poeter & boeter \\
danser 'dancer' & tanser & banser & panser \\
darm 'bowel' & tarm & barm & parm \\
deeg 'dough' & teeg & beeg & peeg \\
dorp 'village' & torp & borp & porp \\
& & & \\
& & &
\end{tabular}


Appendix A (continued)

\begin{tabular}{llll}
\hline Lexical & Incorrect voice & Incorrect place & Incorrect voice \& place \\
\hline page 'page' & bage & tage & dage \\
pauze 'pause' & bauze & tauze & dauze \\
peper 'pepper' & beper & teper & deper \\
pils 'beer' & bils & tils & dils \\
bagger 'mud' & pagger & dagger & tagger \\
basis 'basis' & pasis & dasis & tasis \\
bende 'mess' & pende & dende & tende \\
buidel 'pouch' & puidel & duidel & tuidel \\
\hline
\end{tabular}

Items for Experiment 4

\begin{tabular}{|c|c|c|c|}
\hline Lexical & Incorrect manner & Incorrect place & Incorrect manner \& place \\
\hline \multicolumn{4}{|l|}{ fricatives } \\
\hline suiker 'sugar' & tuiker & fuiker & puiker \\
\hline saldo 'balance' & taldo & faldo & paldo \\
\hline safari 'safari' & tafari & fafari & pafari \\
\hline serie 'series' & terie & ferie & perie \\
\hline zalf 'salf' & dalf & valf & balf \\
\hline zegel 'seal' & degel & vegel & begel \\
\hline zenuw 'nerve' & denuw & venuw & benuw \\
\hline zeep 'soap' & deep & veep & beep \\
\hline feest 'party' & peest & seest & teest \\
\hline fakkel 'torch' & pakkel & sakkel & takkel \\
\hline fiets 'bicycle' & piets & siets & tiets \\
\hline film 'film' & pilm & silm & tilm \\
\hline vangst 'catch' & bangst & zangst & dangst \\
\hline varken 'pig' & barken & zarken & darken \\
\hline vogel 'bird' & bogel & zogel & dogel \\
\hline vuist 'fist' & buist & zuist & duist \\
\hline \multicolumn{4}{|l|}{ plosives } \\
\hline tube 'tube' & sube & pube & fube \\
\hline tarwe 'wheat' & sarwe & parwe & farwe \\
\hline tempo 'speed' & sempo & pempo & fempo \\
\hline tijger 'tiger' & sijger & pijger & fijger \\
\hline dame 'dame' & zame & bame & vame \\
\hline danser 'dancer' & zanser & banser & vanser \\
\hline dieet 'diet' & zieet & bieet & vieet \\
\hline dienst 'service' & zienst & bienst & vienst \\
\hline pols 'wrist' & fols & tols & sols \\
\hline peddel 'paddle' & feddel & teddel & seddel \\
\hline parel 'pearl' & farel & tarel & sarel \\
\hline pels 'fur' & fels & tels & sels \\
\hline barst 'creak' & varst & darst & zarst \\
\hline beeld 'statue' & veeld & deeld & zeeld \\
\hline berg 'mountain' & verg & derg & zerg \\
\hline boter 'butter' & voter & doter & zoter \\
\hline
\end{tabular}

\section{References}

Boersma, P. (1996). Praat: Doing phonetics by computer. Manuscript, University of Amsterdam.
Booij, G. E. (1995). The phonology of Dutch. Oxford: Clarendon Press. Collins, B., \& Mees, I. (1981). The sounds of English and Dutch. Leiden: Leiden University Press. 
Coltheart, M., Curtis, B., Atkins, P., \& Haller, M. (1993). Models of reading aloud: Dual-route and parallel-distributed-processing approaches. Psychological Review, 100, 589-608.

Connine, C. M., Blasko, D. G., \& Titone, D. (1993). Do the beginnings of spoken words have a special status in auditory word recognition? Journal of Memory and Language, 32, 193210.

Gussenhoven, C., \& Bremmer, R. H, Jr. (1983). Voiced fricatives in Dutch: Sources and present-day usage. North - Western European Language Evolution, 2, 55-71.

Jensen, J. T. (1993). English phonology. Amsterdam/Philadelphia: John Benjamins Publishing Company.
Just, M. A., Carpenter, P. A., \& Woolley, J. D. (1982). Paradigms and processes in reading comprehension. Journal of Experimental Psychology: General, 111, 228-238.

Lukatela, G., Eaton, T., Lee, C., \& Turvey, M. T. (2001). Does visual word recognition involve a subphonemic level? Cognition, 78, B41B52.

Milberg, W., Blumstein, S., \& Dworetzky, B. (1988). Phonological factors in lexical access: Evidence from an auditory lexical decision task. Bulletin of the Psychonomic Society, 26, 305-308.

Miller, G. A., \& Nicely, P. E. (1955). An analysis of perceptual confusions among some English consonants. Journal of the Acoustical Society of America, 27, 338-552. 